\title{
The Effects of Gene Polymorphisms in Interleukin-4 on the Susceptibility of Rheumatoid Arthritis in a Iraq Population
}

\author{
Ishraq Abdul Ameer Salih* \\ Department of Biology,Science ForWomen, University of Babylon, Iraq
}

Rabab Omran

Department of Biology,Science, University of Babylon. Iraq

\begin{abstract}
Rheumatoid Arthritis (RA) has been the most disease that recorded high number in Iraqi population, Interleukin-4 (IL-4) have been reported to associate with pathogenesis of rheumatoid arthritis (RA); which it is role of IL-4 genetic polymorphisms in RA. Method: A total of 50 unrelated IRAQ patients with RA and 40 healthy Iraqi volunteers with no family histories of any autoimmune diseases were recruited. The promoter IL-4-590 C/T polymorphisms were genotyped gene polymorphism implemented used RFLP technique. Result:The results show The genotype distributions and allele frequencies of IL-4-590 C/T polymorphisms in RA patients were significantly different from healthy Statistically significant differences were observed in genotypes for IL-4-590 .The frequencies of the T allele on the IL- 4-590 were significantly increased in RA patients. Conclusion. The IL-4-590 promoter polymorphisms may be associated with increased risk of RA and could be used as genetic marker for assessing the susceptibility and severity of RA in Iraqi.
\end{abstract}

Keywords: IL-4 gene; RFLP; Rheumatoid Arthritis.

(c) (i) CC BY: Creative Commons Attribution License 4.0

\section{Introduction}

Rheumatoid arthritis (RA) is a disease of autoimmune disease that causes hope Worm in the joints and chronic inflammatory related with progressive disability, In autoimmune disease, a device begins Immune to your healthy tissues In the case of rheumatoid arthritis, complications in some systems, early death, previous studies show that it was 0.5 to $2 \%$ of the world's population [1].

RA pathogenesis refer to secration many of the pro-inflammatory cytokines such as IL4,IL6 and ather [2, 3]. Furthermore, the HLA-DR loci were estimated to account for only about one-third of the genetic predisposition to RA [4]. A single-nucleotide polymorphism of ccr4 was found to be associated with susceptibility to rheumatoid arthritis in Japanese and Taiwanese population [5, 6]. Many cytokine genes were also playing an important role in its pathogenesis [7]. Interleukin-4 (IL-4) and interleukin-6 (IL-6) are the two most important cytokine genes associated with RA $[8,9]$.

IL-4 is the first discovered B-cell pleiotropic cytokine that promotes proliferation of $\mathrm{T}$ cells and antibodies production of $\mathrm{B}$ cells and plays an important role in the immune system [10, 11]. Therefore, polymorphisms affecting genes of IL-4 and IL-6 can be linked with RA risk and become of great interest to researchers [12]. IL-4590 promoter polymorphism, a C-to-T base substitution, has been suggested to be associated with RA, especially with early pauciarticular juvenile rheumatoid arthritis [13]. Many previous studies examined the association of IL-4 gene polymorphisms with RA [14], but their data are conflicting, so the association of IL-4 gene polymorphisms with RA in Iraq could not be deduced and needs further studies.

\section{Materials and Methods}

\subsection{Sampling and Data Collection}

This a case-control study consisted of 50 patients with RA and 40 healthy persons without a history of immunological diseases as a control group. All subjects signed an informed consent, and clinical data of patients were collected from patient files and questionnaires. Our study was approved by the Research Ethics of the Iraqi Ministry of Health. About $2 \mathrm{ml}$ of whole blood was collected from all subjects.

\subsection{DNA Extraction and Purification}

Genomic DNA was extracted from whole blood collected in EDTA-tubes from all subjects (patients and control individuals) using Genomic DNA Extraction Blood DNA Mini Kit (FAVORGENE). The concentration (ng/ml) and purity $(260 / 280 \mathrm{~nm})$ of the DNA extracts were measured at $260 \mathrm{~nm}$ and $280 \mathrm{~nm}$ with a NanoDrop spectrophotometer (OPTIZEN POP - Korea). 


\subsection{Genotyping}

The candidate SNP ( $r s 11209032$ ) in the il4gene at position IL4 -590C/T was investigated using polymerase chain reaction-restriction fragment length polymorphism (PCR-RFLP) technique. The amplification reaction was done with $5 \mu \mathrm{l}$ of $200 \mathrm{ng} / \mu \mathrm{l}$ of genomic DNA, $12.5 \mu \mathrm{l}$ of1X Master Mix (Promega), $2 \mu \mathrm{l}$ of 10 pmol of each specific primer pair (forward and reverse primer), and completed the volume of $25 \mu \mathrm{l}$ PCR mixture with DNase free water.

The source of the primer was Bioneer (South Korea). Primer sequences of IL4 -590C/T were forward (5'ACTAGGCCTCACCTGATACG-3') and reverse (5'- GTTGTAATGCAGTCCTCCTG3') [12]. The technique for PCR included a pre-denaturing temperature at $95^{\circ} \mathrm{C}$ for $1 \mathrm{~min}$, followed by 35 cycles at $94^{\circ} \mathrm{C}$ for $45 \mathrm{~s} ; 63^{\circ} \mathrm{C}$ for $30 \mathrm{~s}$; and $72^{\circ} \mathrm{C}$ for $1 \mathrm{~min}$ with a final extension at $72^{\circ} \mathrm{C}$ for $10 \mathrm{~min}$. Ten $\mu \mathrm{l}$ of PCR products ( $487 \mathrm{bp}$ in length) was digested according to Promega company protocol, which the digestion reaction mixture (36 $\mu$ l) composed of $0.5 \mu 1$ PsmF1, 2 $\mu \mathrm{l}$ of buffer B, $0.2 \mu \mathrm{l}$ BSA buffer, $7 \mu$ lof $1 \mathrm{X}$ Muti core buffer and $16.3 \mu \mathrm{l}$ of $\mathrm{DH}_{2} \mathrm{O}$; the reaction was incubated at $37^{\circ} \mathrm{C}$ for $16 \mathrm{~h}$. Subsequently, The product was separated on a $1.5 \%$ agarose gel for $45 \mathrm{~min}$ and power 70 volt and 20mA. Finally, The gel was viewed by RedSafe ${ }^{\mathrm{TM}}$ Nucleic Acid Staining (iNtRON) under ultraviolet light. PsmF1 digestion of the PCR product yielded $252 \mathrm{bp}$ for the undigested allele C/C, 192bp and 60bp bp C/T genotype was completely digested into $252192 \mathrm{bp}, 60 \mathrm{bp}$ and T/T genotype $252 \mathrm{bp}$ fragments; all 4 fragments (252 bp, $192 \mathrm{bp}, 60 \mathrm{bp}$ ) corresponded to the heterozygous $\mathrm{C}>\mathrm{T}$ genotype (Figure 1). The frequency of allele calculated according to HardyWeinberg law and the statistical analysis implemented using odd ration at $P$-value $<0.05$.

\section{Results and Discussion}

The results of present study show that the demographic distribution was shown in table (1), the age means were 47.5 \pm 12.48 for control and $38 \pm 10.37$ for patients according to sex female more than male in patients with significant increment, male percentage was 35\%, $18 \%$ in control and patients respectively and female percentage was $65 \%$, $82 \%$ in control and patients respectively, this results deal with international studies that improved that female was more susceptible to the disease than male, this may be because the difference of hormonal activity between male and female also the deference's of behavior and life style $(12,13)$.

Table-1. Some Characteristics of Study Groups

\begin{tabular}{|c|c|c|c|c|}
\hline rs3761548 Genotypes & Cases $($ No. $=50)$ & Controls $($ No. $=40)$ & Test & P-value \\
\hline Age (year) & $47.5 \pm 12.48$ & $38 \pm 10.37$ & $t=0.03^{*}$ & 0.05 \\
\hline \multicolumn{5}{|l|}{ Sex } \\
\hline Male & $18 \%(9)$ & $14) 35 \%($ & \multirow[t]{2}{*}{$X^{2}=0.06$} & \multirow[t]{2}{*}{0.05} \\
\hline Female & $82 \%(41)$ & $26) 65 \%($ & & \\
\hline
\end{tabular}

The results of study show IL4 genotype show significant variation between alleles in patient and control, the CC was appeared in $30 \%$ control while it was $40 \%$ in patients, TT genotype was more frequent in patients (34\%) than control (12.5\%). CT genotype was more frequent in control $(47.5 \%)$ than patients $(26 \%)$, (table, 2) (figure 1). The relative risk analysis show that there is significant variation between patient and control in CC and CT genotype at $\mathrm{p}$ value 0.05 (table 3 ).

Table-2. Distribution of Allele Frequency and Genotype of IL4 in Case-Control Study

\begin{tabular}{l|l|l|l|l|l}
\hline Genotype & Patients N (\%50(100\%) & Control N\% 40(100\%) & TEST X2 & Odd ratio & CI 95\% \\
\hline CC & $20(40)$ & $16(30)$ & $0.02 *$ & 1.26 & $0.46-3.43$ \\
\hline CT & $17(34)$ & $5(12.5)$ & & 1.53 & $0.55-4.18)$ \\
\hline TT & $13(26)$ & $19(47.5)$ & & & \\
\hline OR: Odd Ratio. \\
CI: Confidence Interval.
\end{tabular}

Table-3. The Relative Risk of Genotyping in Study Groups

\begin{tabular}{|c|c|c|c|}
\hline Genotype & Relative risk & CI 95\% & P -value \\
\hline \multicolumn{4}{|l|}{$\mathrm{CC}$} \\
\hline $\mathrm{CT}$ & 72 & $0.72-2.41$ & $0.022 *$ \\
\hline TT & 28 & $0.60-1.97$ & 0.44 \\
\hline
\end{tabular}


Figure-1. Agarose Gel Showing PsmF1 Restriction Profiles of the IL4- -590C/T Polymorphic Sites in Studied Group
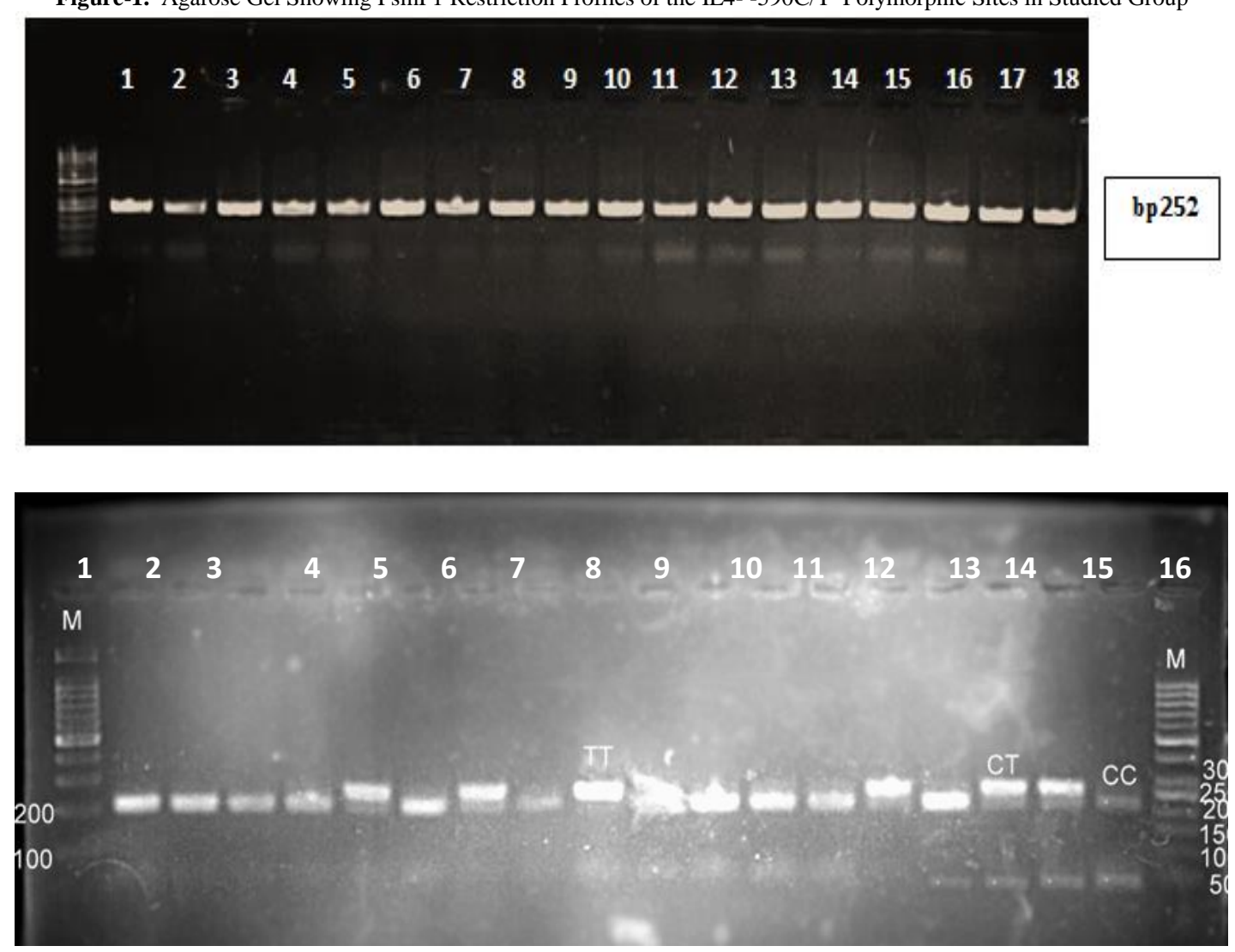

Rheumatoid arthritis (RA) is a common chronic autoimmune disorder characterized by the destruction of articular cartilage and bone, which affects many of patients worldwide. In this study, we investigated whether IL-4 promoter polymorphisms influence the susceptibility of RA in a Iraq population. Our results showed that the TT genotype carriers had markedly higher risk for RA compared with CC genotype carriers for IL-4 promoter polymorphisms, and the CC genotype carriers had markedly higher risk for RA; besides, the T allele of IL-4 promoter polymorphisms promoter polymorphisms had shown an association with susceptibility of RA in a Iraq population.

IL-4 is one of anti-inflammatory cytokine, produced by activated CD4+ lymphocytes, mast cells, and basophils and exerts an important role in the immune system on different cell types [15]. In humans the IL-4 gene has been mapped to chromosome $14 \mathrm{q} 32$ [16].

The IL-4 gene promoter contains many of polymorphic loci, which were reported to influence the susceptibility of many diseases such us RA, including the IL-4-33C/T [17], IL-4-589C/T [18], and IL-4-590C/TIL-4-590C/T were well studied and reported to be associated although the role of the genotype and allele frequencies of with many diseases, such as rheumatoid arthritis [19].

IL-4-gene in association with rheumatoid arthritis has been documented, we did not find any reports with regard to the genetic polymorphisms of IL-4-590C/T with rheumatoid arthritis patients in Iraq population.

In this study, we firstly reported the role of genetic polymorphisms of IL-4 promoter in RA in Iraq population. We found that IL-4-590C/T polymorphisms are associated with the RA risk, and the T allele of IL-4 promoter polymorphisms has significantly increased the susceptibility of RA in Chinese population. This finding suggests that the IL-4-590C/T polymorphisms may be used as a genetic marker for the onset and development of RA in Iraq population.

This finding suggests that, besides the IL-4-590C/T polymorphisms may also be used as another genetic marker for the onset and development of RA in Iraq population.

This study found that the genotype and allele frequencies of IL-4-590C/T polymorphisms are associated with the susceptibility of RA in a Iraq population.

\section{References}

[1] Gambhir, D., Lawrence, A., Aggarwal, A., Misra, R., Mandal, S. K., and Naik, S., 2010. "Association of tumor necrosis factor alpha and IL-10 promoter polymorphisms with rheumatoid arthritis in North Indian population." Rheumatol Int, vol. 30, pp. 1211-1217.

[2] McInnes, I. B. and Schett, G., 2007. "Cytokines in the pathogenesis of rheumatoid arthritis." Nat. Rev. Immunol., vol. 7, p. 429_442.

[3] Firestein, G. S., 2003. "Evolving concepts of rheumatoid arthritis." Nature, vol. 423, p. 356_361.

[4] Kim, J. M. and Kim, H. Y., 2010. "Pathogenesis of rheumatoid arthritis." Journal of the Korean Medical Association, vol. 53, pp. 853-861. 
[5] Frisell, T., Holmqvist, M., Källberg, H., and Klareskog, L., 2013. "Familial risks and heritability of rheumatoid arthritis: role of rheumatoid factor/anti- citrullinated protein antibody status, number and type of affected relatives, sex, and age." Arthritis and Rheumatism, vol. 65, pp. 2773-2782.

[6] Song, G. G., Bae, S. C., Kim, J. H., and Lee, Y. H., 2013. "Interleukin-4, interleukin-4 receptor, and interleukin-18 polymorphisms and rheumatoid arthritis: a meta-analysis." Immunological Investiga-tions, vol. 42, pp. 455-469.

[7] Krabben, A., Wilson, A., and de Rooy, D., 2013. "A7.10 Genetic variants in the IL-4 and IL-4 receptor genes in association with the severity of joint damage in rheumatoid arthritis, a study in seven cohorts." Annals of the Rheumatic Diseases, vol. 72, p. A51.

[8] Song, G. G., Bae, S. C., and Kim, J. H., 2013. "Association between functional Fc receptor-like 3 (FCRL3)$169 \mathrm{C} / \mathrm{T}$ polymorphism and susceptibility to seropositive rheumatoid arthritis in Asians, a meta-analysis." Human Immunology, vol. 74, pp. 1206-1213.

[9] Krabben, A., Wilson, A., and de Rooy, D., 2013. "Association of genetic variants in the IL4 and IL4R genes with the severity of joint damage in rheumatoid arthritis, a study in seven cohorts." Arthritis \& Rheumatism, vol. 65, pp. 3051-3057.

[10] Kurko, J., Besenyei, T., Laki, J., Glant, T. T., Mikecz, K., and Szekanecz, Z., 2013. "Genetics of rheumatoid arthritis - a comprehensive review." Clinical Reviews in Allergy \& Immunology, vol. 45, pp. $170-179$.

[11] Song, G. G., Bae, S. C., Kim, J. H., and Lee, Y. H., 2013. "Interleukin-4, interleukin-4 receptor, and interleukin-18 polymorphisms and rheumatoid arthritis: a meta-analysis." Immunological Investiga- tions, vol. 42, pp. 455-469.

[12] Peng, H., Wang, W., and Zhou, M., 2013. "Associations of interleukin-4 receptor gene polymorphisms (Q551R, I50V) with rheumatoid arthritis: evidence from a meta-analysis." Genetic Testing and Molecular Biomarkers, vol. 17, pp. 768-774.

[13] Suppiah, V., 2006. "Genetics of autoimmune diseases, a study of immuno- regulatory genes, CTLA4, IL-4, IL-4RA, SOCS3, IFNG and IL-26 in multiple sclerosis, rheumatoid arthritis and juvenile idiopathic arthritis." [Ph.D. thesis], Queen's University of Belfast, Belfast, Northern Ireland.

[14] Hussein, Y. M., El-Shal, A. S., Rezk, N. A., Abdel Galil, S. M., and Alzahrani, S. S., 2013. "Influence of interleukin-4 gene polymorphisms and interleukin-4 serum level on susceptibility and severity of rheumatoid arthritis in Egyptian population." Cytokine, vol. 61, pp. 849-855.

[15] Ji, Y., Sun, S., and Xu, A., 2012. "Activation of natural killer T cells promotes M2 macrophage polarization in adipose tissue and improves systemic glucose tolerance via interleukin-4 (IL-4)/STAT6 protein signaling axis in obesity." Journal of Biological Chemistry, vol. 287, pp. 13561-13571.

[16] Chatterjee, A. A. R. and Dhole, T. N., 2009. "Association of IL- 4589 C/T promoter and IL-4R I50V receptor polymorphism with susceptibility to HIV-1 infection in North Indians." Journalof Medical Virology, vol. 81, pp. 959-965.

[17] Gervaziev, Y. V., Olenina, L. V., Krasotkina, J. V., Lupatov, A. Y., Mazurina, S., and Gervazieva, V. B., 2010. "Oct-1 is responsible for the C-33T polymorphism effect in the IL-4 promoter." International Journal of Immunogenetics, vol. 37, pp. 13-20.

[18] Pawlik, A., Wrzesniewska, J., Florczak, M., Gawronska-Szklarz, B., and Herczynska, M., 2005. "The -590 IL-4 promoter polymorphism in patients with rheumatoid arthritis." Rheumatology Interna- tional, vol. 26, pp. 48-51.

[19] Kurko', J., Besenyei, T., Laki, J., Glant, T. T., Mikecz, K., and Szekanecz, Z., 2013. "Genetics of rheumatoid arthritis - a comprehensive review." Clinical Reviews in Allergy \& Immunology, vol. 45, pp. $170-179$ 